\title{
The effectiveness of sequencing virtual patients with lectures in a deductive or inductive learning approach
}

Citation for published version (APA):

Marei, H. F., Donkers, J., Al-Eraky, M. M., \& van Merrienboer, J. J. G. (2017). The effectiveness of sequencing virtual patients with lectures in a deductive or inductive learning approach. Medical Teacher, 39(12), 1268-1274. https://doi.org/10.1080/0142159X.2017.1372563

Document status and date:

Published: 01/01/2017

DOI:

10.1080/0142159X.2017.1372563

Document Version:

Publisher's PDF, also known as Version of record

Document license:

Taverne

Please check the document version of this publication:

- A submitted manuscript is the version of the article upon submission and before peer-review. There can be important differences between the submitted version and the official published version of record.

People interested in the research are advised to contact the author for the final version of the publication, or visit the DOI to the publisher's website.

- The final author version and the galley proof are versions of the publication after peer review.

- The final published version features the final layout of the paper including the volume, issue and page numbers.

Link to publication

\footnotetext{
General rights rights.

- You may freely distribute the URL identifying the publication in the public portal. please follow below link for the End User Agreement:

www.umlib.nl/taverne-license

Take down policy

If you believe that this document breaches copyright please contact us at:

repository@maastrichtuniversity.nl

providing details and we will investigate your claim.
}

Copyright and moral rights for the publications made accessible in the public portal are retained by the authors and/or other copyright owners and it is a condition of accessing publications that users recognise and abide by the legal requirements associated with these

- Users may download and print one copy of any publication from the public portal for the purpose of private study or research.

- You may not further distribute the material or use it for any profit-making activity or commercial gain

If the publication is distributed under the terms of Article $25 \mathrm{fa}$ of the Dutch Copyright Act, indicated by the "Taverne" license above, 


\section{The effectiveness of sequencing virtual patients with lectures in a deductive or inductive learning approach}

Hesham Fathi Marei, Jeroen Donkers, Mohamed Mostafa Al-Eraky \& Jeroen J. G. van Merrienboer

To cite this article: Hesham Fathi Marei, Jeroen Donkers, Mohamed Mostafa Al-Eraky \& Jeroen J. G. van Merrienboer (2017) The effectiveness of sequencing virtual patients with lectures in a deductive or inductive learning approach, Medical Teacher, 39:12, 1268-1274, DOI: 10.1080/0142159X.2017.1372563

To link to this article: https://doi.org/10.1080/0142159X.2017.1372563

View supplementary material

Published online: 22 Sep 2017.

Submit your article to this journal $\widetilde{ }$

Џll Article views: 704

Q View related articles ¿

View Crossmark data $₫$

Citing articles: 2 View citing articles $\widetilde{ }$ 


\title{
The effectiveness of sequencing virtual patients with lectures in a deductive or inductive learning approach
}

\author{
Hesham Fathi Marei ${ }^{a, b}$, Jeroen Donkers ${ }^{c}$, Mohamed Mostafa Al-Eraky ${ }^{\text {d,e }}$ and Jeroen J. G. van Merrienboer ${ }^{c}$ \\ aBiomedical Dental Sciences Department, College of Dentistry, University of Dammam, Dammam, Saudi Arabia; ${ }^{b}$ Department of Oral and \\ Maxillofacial Surgery, Faculty of Dentistry, Suez Canal University, Ismailia, Egypt; 'Department of Educational Development and \\ Research, School of Health Professions Education, Maastricht University, Maastricht, Netherlands; ${ }^{\mathrm{d} D e v e l o p m e n t}$ and Academic Initiatives

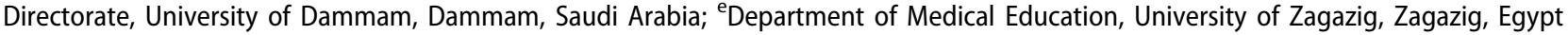

\begin{abstract}
Background: Virtual patients (VPs) can be sequenced with other instructional methods in different ways.

Aim: To investigate the effect of sequencing VPs with lectures in a deductive approach, in comparison with an inductive approach, on students' knowledge acquisition, retention, and transfer.

Methods: For two different topics, 84 out of 87 students have participated in the lecture and VP sessions. Students from female and male campuses have been randomly assigned to one of the two learning approaches (deductive and inductive) yielding four experimental groups. Each group received a lecture session and an independent VP learning activity, which either followed the lecture session in the deductive group or preceded it in the inductive group. Students were administrated knowledge acquisition and retention written tests as well as transfer tests using two new VPs.

Results: There was no significant effect for the learning approach on knowledge acquisition or retention, while for knowledge transfer, males have benefited from the inductive approach in topic 1 while in the more complex topic 2 , they have benefited from the deductive approach. On the other hand, females seem to be largely unaffected by learning approach.

Conclusions: Sequencing VPs in inductive and deductive learning approaches leads to no significant differences on students' performance when full guidance is offered in the inductive approach.
\end{abstract}

\section{Introduction}

Virtual patients (VPs) are specific types of computer-programs that simulate real-life clinical scenarios; learners imitate the roles of health care providers to obtain a history, conduct a clinical examination, and make diagnostic and therapeutic decisions (Cook and Triola 2009).

The potentials of VPs in promoting deep learning, reducing medical errors, knowledge gain and transfer (Berman et al. 2016) have motivated educators to question how to use and sequence VPs with other instructional methods in order to have tangible effects on learning outcomes (Cook and Triola 2009; Cook et al. 2010; Ellaway et al. 2015) and positive influence on students' perceptions (Huwendiek et al. 2013).

Virtual patients can be sequenced with other instructional methods in different ways (Huwendiek et al. 2013), as they can be presented either before the lecture (inductive approach) or after the lecture (deductive approach). A deductive learning approach refers to introducing theoretical knowledge followed by its practical applications and examples (Gavriel 2015). In such an approach, the students attend a lecture before handling an authentic problem or a task (Prince and Felder 2006). The instructions presented in the lecture serve as supportive information for task execution or problem solving (Vandewaetere et al. 2015).

On the other hand, the inductive approach refers to the process of moving from real practical situations towards theoretical and generalized concepts (Gavriel 2015). In such

\section{Practice points}

- Sequencing virtual patients (VPs) after lectures in a deductive approach could facilitate knowledge transfer when complex topics are taught.

- Sequencing VP in an inductive or deductive approach should carry differences in the amount of guidance based on students' prior knowledge and complexity of VPs.

- VPs' typology should be followed in describing their features to allow better comparison between the effects obtained in different VPs' studies.

an approach, the student is confronted by a problem followed by another form of instruction (Prince and Felder 2006). The problem stimulates the students to discover their knowledge gap, which first raises their situational interest and increases their desire to learn. Once students get saturated with knowledge through other forms of instruction, their desire to learn decreases (Schmidt et al. 2011). Situational interests are interests that are triggered temporarily by environmental factors such as task instructions or an engaging text, thus these interests are more or less under the direct control of educators (Schraw et al. 2001).

A deductive learning approach is more applicable in situations that involve large group teaching, and it is the 
dominant instructional approach in a discipline-based curriculum (Harden et al. 1984). It might work better for learners with previous experience, as they already have knowledge structures (schema) relevant to the topic in their long-term memory. Therefore, the process of associating new knowledge elements with each other (schema construction) or with prior knowledge (schema elaboration) results in a germane cognitive load on working memory which enhances learning (Van Merrienboer and Sweller 2010). Although this learning approach is criticized for being more teacher-centered (Harden et al. 1984), it still can positively influence student achievement in an activelearning classroom, provided that teachers are experts, can express themselves in clear language and show their concerns for their students (Rotgans and Schmidt 2011).

On the other hand, the inductive approach works well in small group settings (like problem-based learning), is more appropriate for learners with relative low expertise who are eager to learn more about the topic and, therefore, it provokes their situational interest (Schmidt et al. 2011). Although it is considered as a student-centered learning approach, as students have to construct their own knowledge by selecting and integrating information across multiple literature resources, still the role of the tutor is crucial in such an approach. The tutor provides scaffolding to the learners by guiding them to the relevant learning resources, facilitating the discussion and creating a learning environment in the classroom that leads to exchange of ideas (Schmidt et al. 2011).

In a deductive approach, VPs can be used as an authentic context for knowledge application in an independent learning activity that follows, for instance, a lecture. In an inductive approach, VPs can be used as a trigger for students to be aware of their knowledge gap. In both approaches, presenting the students with problems through VPs gives more meaning or relevance to the acquired knowledge (Fyrenius et al. 2005), and it is determined that the level of acquisition and retention of meaningful knowledge is higher than that of meaningless knowledge (Fyrenius et al. 2005; Schmidt and Rikers 2007). Students store their own interpretation of what is lectured rather than store information as taught. Therefore, when students apply what they learned, acquisition, retention and transfer are enhanced (Schmidt et al. 2015). Knowledge transfer to new settings or problems, different from the original learning context, requires variability in practicing authentic problems in a real or simulated environment to increase the number and complexity of schemata in long-term memory (Gentile 2000; Van Merrienboer and Sweller 2010).

Jones et al. (2008) evaluated students' perception toward both deductive and inductive learning approaches. They stated that the inductive approach is better than the deductive approach for generating students' interest, remembering facts, and comprehension, while the deductive approach enabled a greater content coverage in a given time. Others argued that solving complex problems without any prior knowledge of the topic or appropriate support or guidance by a tutor imposes high load on working memory and leads to slow and inefficient learning (Kirschner et al. 2006; Clark et al. 2012). Wijnia et al. (2014) found that studying integrated model answers during self-study in a PBL setting (inductive approach) is more effective than letting students construct their own answers by selecting and integrating information across multiple literature resources. Such result was accompanied by equal investment of mental effort during the study phase of both groups, which indicates that even within an inductive learning approach, still there is an effective role for direct instructions.

Although Huwendiek et al. (2013) reported a qualitative analysis of students' perceptions toward the optimal sequence of VPs with other instructional methods, still such sequence might not be the most effective one. Our study aimed to investigate the effect of sequencing VPs with lectures on students' knowledge acquisition, retention and transfer, leading to the research question: Is sequencing VPs with lectures in a deductive approach (i.e. VP after lecture) more effective than sequencing them in an inductive approach (i.e. VP before lecture), on students' knowledge acquisition, retention, and transfer?

\section{Method}

\section{Participants}

The study was conducted at a dental school that involves two separate campuses for male students and female students. For the purpose of this study, both male and female students were invited to attend the teaching, learning and assessment sessions in the same classroom but at different times for the two genders. All students who were registered for the first time in the oral and maxillofacial surgery course for the academic year 2016/2017 (first semester) were invited to participate voluntary in the study $(N=87)$. The study involved the use of eight VPs for learning and assessment purposes. It targeted two topics, which are impacted wisdom teeth (topic 1) and maxillofacial trauma (topic 2) within the same course.

The male students were randomly assigned into two groups as follow: male/inductive $(n=22)$ and male/deductive $(n=21)$. The same was true for the female students, who were randomly assigned into female/inductive $(n=22)$ and female/deductive $(n=22)$ groups.

\section{Materials}

\section{Virtual patients}

Eight VPs were used. Four of which (two VPs per topic) were used in the VP learning activity sessions, while the other four (two VPs per topic) were used for assessment purpose. They have been delivered as computer-based transfer tests two weeks after the lecture and VP learning sessions.

For the VP sessions, the VPs had a branched-tree dynamic design, and were based on real patient scenarios. Real patient radiographs, lab results, intra-oral photos, and records for other special investigations were used at different stages of VPs path, while two-dimensional graphics were used to represent different clinical settings, and different characters within the VPs (Supplementary Appendix 1).

During practice, each VP branched based on student's choices on crucial decisions such as definitive diagnosis, selecting a specific surgical procedure, or admitting the patient to a hospital. The students selected each decision from a shortlist of options. If correct, the student stayed in the main VP path, while if wrong, the student followed the consequences of the decision taken till the next node, 
where he/she was directed back to the main stream. The VP provided immediate feedback to the students on knowledge questions as either correct or incorrect, while the overall score, which was calculated based on the total number of correct answers, was displayed after the VP had been completed by students.

For assessment, the VPs' design was similar to the VPs that were used in the VP sessions but they provide only a summary report that shows the final score, which is the percentage of correct items to the total number of items.

Measurement instruments. Three tests were constructed for each topic: a knowledge acquisition test (KA), a knowledge retention test $(K R)$, and a knowledge transfer test (KT). KA and KR were paper-based tests that are similar in format, difficulty and number of items, while KT was a computer-based test that involved the use of four VPs (two VPs for each topic).

The KA tests for topics 1 and 2 were delivered immediately after the lecture and VP sessions of topics 1 and 2, respectively. Each test involved 25 multiple choice questions (MCQs), in which each question involves four options. The KR tests were unannounced and delivered two weeks after the immediate KA tests of topics 1 and 2, respectively.

All questions were retrieved from the department item bank that contains questions that have been used before and showed a difficulty index of 0.2 to 0.8 and a discrimination index larger than 0.1. Two subject matter experts established the content validity of test items through test blueprint, and test revision. They also developed and agreed on the scoring key for all questions. The tests were scored electronically. All paper-based tests were constructed to measure factual knowledge (e.g. the complication associated with specific procedure, the risk of damage to certain vital structure, specific terms that describe certain phenomena, the signs and symptoms of specific conditions), conceptual knowledge (e.g. classify an impacted tooth or a specific fracture, estimate the degree of difficulty of specific surgical procedure based on the presented vignette), and strategic knowledge (e.g. request a specific investigation, reach a diagnosis, choose a specific treatment option, prescribe a specific medication based on the patients' condition in the presented vignette). For the KA and KR tests, we used the same blueprint and difficulty selection. The reliability (Cronbach's alpha) of items of topics 1 and 2 were 0.73 and 0.72 , respectively.

The computer-based transfer tests (KT) for topics 1 and 2 were delivered unannounced immediately after the retention tests. Each test involved two new VPs. Two independent subject matter experts have validated the new VPs to ensure that they present new situations that are relevant to the VPs used in the learning sessions. The students took the transfer test independently by logging in to their account on the university learning management system. The VP software did all scoring automatically. The final score equals the percentage of correct answers. The results of the tests were displayed on the final screen of the VP and were collected by the tutor. A copy of students' scores was recorded on the university learning management system for future feedback. The tests targeted mainly strategic knowledge of the relevant topics. The student had to request the appropriate radiograph, interpret the relevant lab test, choose the correct diagnosis, admit the VP to the hospital, select a specific surgical procedure, consent the patient before surgery, and finally recommend the clinical management for a specific complication.

\section{Procedure}

The interventions consisted of two parts: a lecture session, which was the same per topic for all experimental groups, and an independent VP learning activity, which either followed the lecture session in the deductive group or preceded it in the inductive group (Figure 1).

Lecture session: all students received the same lecture that involved a PowerPoint presentation for $90 \mathrm{~min}$ with a 10 -min break halfway. The lecture was designed and presented to target predefined learning objectives of both topics. The objectives were mainly related to diagnosis of specific conditions through identifying the relevant history, signs and symptoms, required investigations. The lecture also covered formulation of treatment plans through making the students aware of the indications and contra-indications of every treatment option, and factors that would affect the outcome of specific surgical procedures. Two subject-matter experts revised the lecture content and structure, and the same faculty member delivered the lecture to both the male and female groups.

Virtual patient session: each student accessed a computer in the computer lab and worked individually on two different VPs from the beginning till the end of the session, which lasted for one hour. The role of the tutor was limited to helping the students with any technical problems during their interaction with the VPs.

One month later, topic 2 was presented in the same manner as the first topic. Student groups who have practiced the VPs after the lecture session (deductive) in topic 1 were now asked to practice the VPs before the lecture session (inductive) in topic 2 and vice versa.

\section{Data collection and analysis}

Data were collected by the college's statistical unit then coded and analyzed using SPSS Software (SPSS 22.0, SPSS Inc., Chicago, IL, USA). For both topics 1 and 2, two-way ANOVA was used to measure the influence of the learning approach (deductive/inductive) and gender (male/female) on the scores for $\mathrm{KA}, \mathrm{KR}$, and $\mathrm{KT}$ (dependent variables). A $p$ value less than 0.05 is considered significant.

\section{Ethical approval}

The study was reviewed and approved by the University Ethical Committee. IRB number: IRB-2015-02-099.

\section{Results}

Eighty-four out of 87 students have participated in the lecture and VP sessions of topic 1 (43 females and 41 males) and topic 2 (44 females and 40 males).

Table 1 provides the means, standard deviations for all scores of topics 1 and 2 per learning approach (deductive and inductive) and gender (males and females). KA1 is the knowledge acquisition test, KR1 is the knowledge retention 

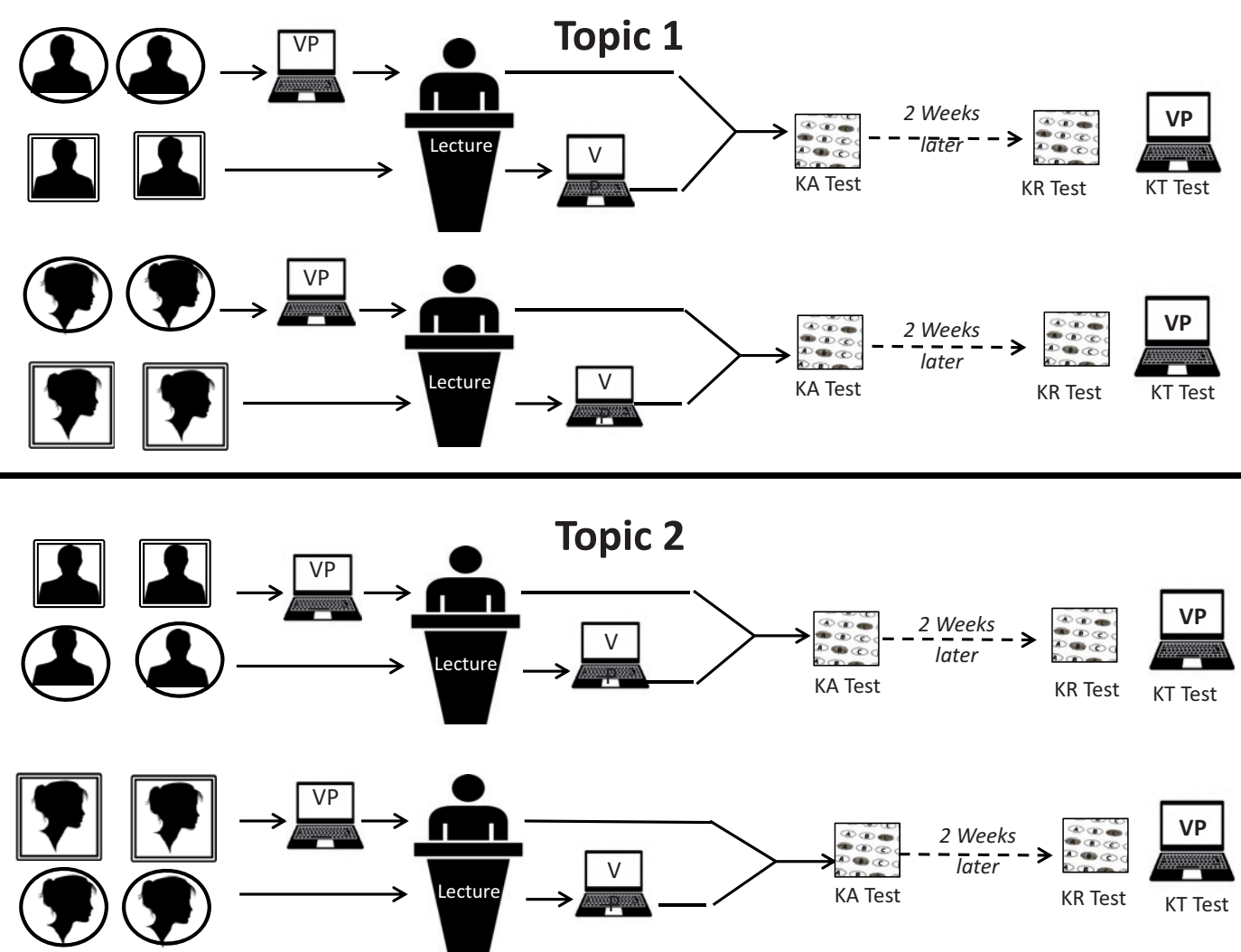

Figure 1. The process of using VPs in both inductive and deductive approaches followed by three tests for: knowledge acquisition (KA), knowledge retention (KR) and knowledge transfer (KT). One month later, student groups who have been involved in VPs after the lecture in topic 1 were asked to practice VPs before the lecture in topic 2 and vice versa.

Table 1. Means and standard deviations for all scores of topics 1 and 2 per learning approach (deductive, inductive) and gender (males and females).

\begin{tabular}{|c|c|c|c|c|c|c|c|c|c|c|}
\hline & \multicolumn{9}{|c|}{ Topic 1} & \multirow[b]{4}{*}{$p$ Value } \\
\hline & \multicolumn{4}{|c|}{ Males } & \multicolumn{4}{|c|}{ Females } & & \\
\hline & \multicolumn{2}{|c|}{ Inductive $(n=20)$} & \multicolumn{2}{|c|}{ Deductive $(n=21)$} & \multicolumn{2}{|c|}{ Inductive $(n=22)$} & \multicolumn{2}{|c|}{ Deductive $(n=21)$} & & \\
\hline & $M$ & $S D$ & $M$ & $S D$ & $M$ & $S D$ & $M$ & $S D$ & & \\
\hline KA1 & 78.2 & 9.4 & 75.8 & 9.2 & 87.8 & 9.1 & 87.4 & 10.0 & $>0.05$ & \\
\hline KR1 & 59.6 & 16.0 & 55.2 & 10.7 & 68.9 & 11.9 & 63.6 & 12.5 & $>0.05$ & \\
\hline \multirow[t]{4}{*}{ KT1 } & 72.8 & 10.7 & 66.4 & 8.0 & 73.5 & 10.8 & 77.6 & 10.5 & $<0.05^{*}$ & \\
\hline & \multicolumn{9}{|c|}{ Topic 2} & \\
\hline & \multicolumn{4}{|c|}{ Males } & \multicolumn{4}{|c|}{ Females } & & \\
\hline & \multicolumn{2}{|c|}{ Inductive $(n=20)$} & \multicolumn{2}{|c|}{ Deductive $(n=20)$} & \multicolumn{2}{|c|}{ Inductive $(n=22)$} & \multicolumn{2}{|c|}{ Deductive $(n=22)$} & $p$ Value & \\
\hline KA2 & 68.0 & 13.8 & 71.8 & 13.0 & 72.0 & 10.7 & 64.3 & 10.1 & $<0.05^{*}$ & \\
\hline KR2 & 53.0 & 12.0 & 55.4 & 13.6 & 71.6 & 10.0 & 67.0 & 9.7 & $>0.05$ & \\
\hline KT2 & 39.0 & 9.6 & 50.2 & 9.1 & 49.3 & 9.9 & 47.9 & 14.7 & $<0.05^{*}$ & \\
\hline
\end{tabular}

KA1 is knowledge acquisition test, KR1 is knowledge retention test, and KT1 is knowledge transfer test in topic 1. KA2, KR2, and KT2 are the same tests for topic 2.

${ }^{*} \mathrm{~A} p$ value less than 0.05 is considered significant.

test, and KT1 is the knowledge transfer test in topic 1. KA2, $K R 2$, and KT2 are the same tests for topic 2.

For topic 1, there was no significant effect of learning approach on scores of different tests (Figure 2(a)). However, there was a significant effect for gender $F(1,83)=26.4$, $p<0.05, \eta p^{2}=0.24$, as females $(M=87.6, S D=9.4)$ scored significantly higher than males $(M=76.9, S D=9.2)$ in $K A 1$. The same was true for $\mathrm{KR} 1 ; F(1,83)=9.8, p<0.05$, $\eta p^{2}=0.10$, and $\mathrm{KT} 1 ; F(1,83)=7.9, p<0.05, \eta p^{2}=0.09$. However, the main effect of gender on KT1 cannot be sensibly interpreted because there is a disordinal interaction.

There was a significant effect for the interaction between gender and learning approach on KT1; $F$ (1, $83)=4.9, p<0.05, \eta p^{2}=0.05$, The males do better in the inductive strategy $(M=72.8, S D=10.7)$ than in the deductive strategy $(M=66.4, S D=8.0)$, but the opposite is true for the females, who do somewhat better in the deductive strategy $(M=77.6, S D=10.5)$ than in the inductive strategy $(M=73.5, S D=10.8)$.

For topic 2, there was no significant effect of the learning approach on KA2 and KR2 (Figure 2(b)). However, there was a significant effect for learning approach on KT2; $F$ (1, $83)=4.0, \quad p<0.05, \eta p^{2}=0.04$ as the deductive group $(M=49.0, S D=12.3)$ scored significantly higher than the inductive group $(M=44.4, S D=10.9)$. However such effect cannot be sensibly interpreted because, again, there is a disordinal interaction. As shown in Table 1, there is a significant effect for the interaction between gender and learning approach on $\mathrm{KT} 2 ; F(1,83)=6.6, p<0.05$, $\eta p^{2}=0.07$, the females $(M=49.3, S D=9.9)$ outperform the males $(M=39.0, S D=9.6)$ in the inductive approach, but in the deductive approach, the females $(M=47.9, S D=14.7)$ 
(a)

\section{Score}

100

80

60

40

20
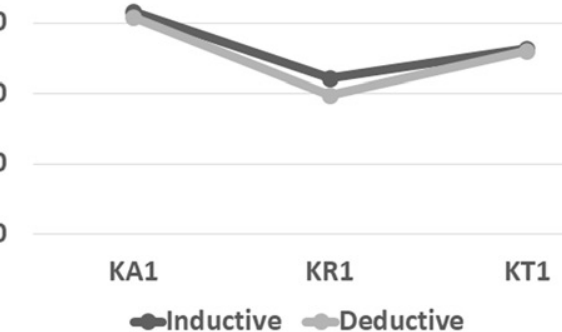

(b)

Score

100

80

60

40

20
Topic 2

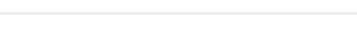

(1)

Figure 2. Students' scores in different tests of topics 1 (a) and 2 (b) per learning approach.

do not score higher than the males $(M=50.2$, SD $=9.1)$. Therefore, males profit more from a deductive approach $(M=50.2$, SD $=9.1)$ compared to an inductive approach $(M=39.0, \mathrm{SD}=9.6)$.

In regard to the effect of gender, there was a significant effect $F(1,83)=36.8, p<0.05, \eta p^{2}=0.31$; as females $(M=69.3, \mathrm{SD}=10.0)$ scored significantly higher than males $(M=54.2, S D=12.7)$ in $K R 2$. There was also a significant effect for the interaction between gender and learning approach on KA2; $F(1,83)=4.7, p<0.05, \eta p^{2}=0.05$, the females profit from an inductive approach $(M=72.0$, SD $=10.7)$ compared to a deductive approach $(M=64.3$, SD $=10.1$ ), while the males, in contrast, profit somewhat from a deductive approach $(M=71.8, S D=13.8)$ compared to an inductive approach $(M=68.0, \mathrm{SD}=13.8)$.

\section{Discussion}

The current study explored the effects of sequencing VP with lecture, in two different learning approaches, on students' knowledge acquisition, retention, and transfer. The study showed no significant difference between students' scores in knowledge acquisition and retention in both topics when the VP is sequenced in an inductive or a deductive approach. In regard to knowledge transfer, there was no significant difference between both learning approaches on students' scores in topic 1, while for topic 2, the deductive group scored significantly higher than the inductive group. We could, however, not sensibly interpret such effect due to a disordinal interaction between gender and learning approach.

We attribute the lack of difference between both learning approaches on students' performance to the level of guidance in both approaches. The deductive approach moved from theory to application using the VPs and the inductive approach presented the problem then the theory, yet direct instruction was provided in both approaches. In instructional design, the level of guidance could vary from totally unguided discovery to full guidance through direct instruction. Our study might have shown a difference in favor of the inductive approach if the students were given an opportunity and enough time to explore learning resources to find answers for questions presented in the VPs.

Yet, when we consider gender as an independent variable, males scored higher in the inductive approach in topic 1 and in the deductive approach in topic 2 on the knowledge transfer tests. Females, however, seem to be largely unaffected by learning approach. We attribute the differences in the male results to the nature of the contents provided in topics 1 and 2 .

In topic 1, the VP session addressed one specific condition (impacted wisdom teeth). Students interpreted signs and symptoms, requested the relevant investigations and formulated a treatment plan that is relevant to one condition only in a purely convergent type of thinking. Therefore, students were able to manage the cognitive load of topic 1 that was most likely within the capacity of working memory because it was only one condition.

There are different types of cognitive loads that can collectively impair learning if they overload working memory capacity (Young et al. 2014). Intrinsic load, which is relevant to the given content, is a function of the complexity of the material, that is, the number of elements presented (amount of given content) and the interaction between such elements (similarities in signs and symptoms, investigations, treatment plans of different conditions) (Young et al. 2014). The extraneous load depends on the quality of instruction and the surrounding physical environment (Choi et al. 2014; Young et al. 2014). In our study, all groups received the instructions in the same classrooms, so we assume that the physical environment effect was the same.

On the other hand, topic 2 (maxillofacial trauma) was relatively more challenging because it addressed multiple conditions. During the VP session, students had to interpret signs and symptoms that are relevant to fracture mandible, mid-face, zygoma and orbit and then formulate a treatment plan based on different clinical and radiographic findings. Such conditions involved interactions between multiple elements. In other words, there were overlaps between signs, symptoms, radiographic investigations and methods of fixations of different fractures. Such interactivity resulted in a high intrinsic cognitive load.

The male/inductive group might not be able to handle the intrinsic load of topic 2 when exposed to the VP before the lecture. The knowledge gap could have been big enough to hinder rather than stimulate students' situational interest. Previous studies showed that complex problems without any prior knowledge of the topic imposes high load on working memory and leads to slow and inefficient learning (Clark et al. 2012), and the situation could be even worse if minimal guidance is provided to novice students working on complex problems (Kirschner et al. 2006), as was the case in the current study. On the other hand, the male/deductive group was able to process and store some 
information in long-term memory during the lecture, which resulted in attaining higher scores for the males/deductive than the male/inductive group in Knowledge transfer test of topic 2.

The high intrinsic load of topic 2 did not only hinder the ability of the male/inductive group to construct a wellorganized knowledge schema, but it affected generally knowledge acquisition, retention and transfer of both groups as there was a trend of lower scores for topic 2 when compared with students scores in topic 1. Both groups had to deal with the full complex problems in VPs during one learning session, however managing the intrinsic cognitive load requires dealing with isolated elements (low element interactivity) first and then gradually works up to the tasks in their full complexity (Van Merrienboer and Sweller 2010).

In topic 1, students in both approaches attained high scores in KA and KT. We may consider such results as a form of productive success. Productive success is the ability of students to perform well in the shorter term (KA) in combination with effective learning (solving real problems) in the longer term (KT) (Kapur 2016). The main reason behind such performance is the appropriate correlation between the amounts of guidance (direct instructions before or after the VP in our study), complexity of the presented problems (VPs), and the students' prior knowledge (Kapur 2016).

In topic 2, there was a drop in scores in KT when compared to KA for all groups. We consider the low achievement in KT a form of unproductive success. Unproductive success is the ability of students to perform well on the shorter term (KA) without effective learning in the longer term (KT) (Kapur 2016). The main reason behind such phenomena is that students get benefit from the direct instructions without any added value for the given problems (VPs). In direct instructions, novice students do not have the necessary prior knowledge differentiation to be able to notice and encode critical features of domain knowledge, which might lead to underperformance that is not so much in terms of acquisition but more in conceptual understanding and transfer (Kapur 2016).

Our study has provided a practical implication for the use and sequence of VPs with lectures. The study suggests that sequencing VPs in either an inductive or deductive approach does not make a significant difference on students' performance when full guidance is offered in the inductive approach. Moreover, we imply that complex topics are preferably presented using VPs in a deductive learning approach, which is aligned with students' preferences in Huwendiek et al. (2013) study. However our suggestion would profit from future studies that use larger number of VPs.

Our study is not without limitations. It has abstracted the inductive learning approach to presenting the VP (problem) before the lecture (direct instruction) without allowing the students to search and integrate information independently across multiple learning resources. In our view, sequencing VP in an inductive or deductive approach should carry differences in the amount of guidance and complexity of both the VP and the lecture to optimally scaffold learning (e.g. more guidance and possibly less complex VP needed if prior to lecture). However, our aim was to ensure that there is no variability in the presented content between the inductive and deductive groups. Therefore, direct instruction (lecture) was provided in the inductive approach to cover exactly the same content as in the deductive approach. The study has also involved gender as a factor in its design, which was mainly due to cultural factors as males and females are separated in two different campuses. Future research would benefit from exploring the effect of sequencing VP and lecture with different amount of guidance and complexity using large number of VPs on other outcomes variables such as performance on real patients.

\section{Conclusions}

Sequencing VPs in inductive and deductive learning approaches leads to no significant difference on students' performance when full guidance is offered in the inductive approach.

\section{Acknowledgements}

Authors would like to thank all the members of Oral and Maxillofacial Surgery Division who revised the lectures content and established the content validity of the different tests.

\section{Disclosure statement}

The authors report no conflicts of interest. The authors alone are responsible for the content and writing of the article.

\section{Glossary}

Deductive learning approach: Introducing theoretical knowledge followed by its practical applications and examples. In such an approach, the students attend a lecture before handling an authentic problem or a task. The instructions presented in the lecture serve as supportive information for task execution or problem solving.

Inductive learning approach: The process of moving from real practical situations towards theoretical and generalized concepts. In such an approach, the student is confronted by a problem followed by another form of instruction. The problem stimulates the students to discover their knowledge gap, which first raises their situational interest and increases their desire to learn.

\section{Notes on contributors}

Hesham F. Marei, MSc, FDSRCS (Eng.), PhD (OMFS), MHPE is an Associate Professor and Consultant of Oral and Maxillofacial Surgery, at College of Dentistry, Imam Abdulrahman Bin Faisal University, Saudi Arabia and Faculty of Dentistry, Suez Canal University, Egypt. Dr. Marei is currently a PhD fellow at School of Health Professions Education, Maastricht University, Netherlands.

Jeroen Donkers, PhD is an Assistant Professor, at the Department of Educational Development and Research, Faculty of Health, Medicine, and Life Sciences, Maastricht University, Netherlands.

Mohamed M. Al-Eraky, MBBCh, MSc, MMEd, PhD is an Assistant Professor of Medical Education. He is currently appointed as Director of Development \& Academic Initiatives at the Vice-President Office for Academic Affairs at Imam Abdulrahman Bin Faisal University, Saudi Arabia.

Jeroen J. G. van Merrienboer, $\mathrm{PhD}$ is a Professor of Learning and Instruction, at the Department of Educational Development and Research, Faculty of Health, Medicine and Life Sciences, Maastricht 
University, Netherlands. He is the Research Director of the School of Health Professions Education.

\section{References}

Berman NB, Durning SJ, Fischer MR, Huwendiek S, Triola MM. 2016 The role for virtual patients in the future of medical education. Acad Med. 91:1217-1222.

Choi H, Van Merrienboer JJ, Paas F. 2014. Effects of the physical environment on cognitive load and learning: toward a new model of cognitive load. Educ Psychol Rev. 26:225-244.

Clark R, Kirschner PA, Sweller J. 2012. Putting students on the path to learning: the case for fully guided instruction. Am Educ. 36:6-11.

Cook DA, Erwin PJ, Triola MM. 2010. Computerized virtual patients in health professions education: a systematic review and meta-analysis. Acad Med. 85:1589-1602.

Cook DA, Triola MM. 2009. Virtual patients: a critical literature review and proposed next steps. Med Educ. 43:303-311.

Ellaway R, Topps D, Lee S, Armson H. 2015. Virtual patient activity patterns for clinical learning. Clin Teach. 12:267-271.

Fyrenius A, Bergdahl B, Silen C. 2005. Lectures in problem-based learning - why, when and how? An example of interactive lecturing that stimulates meaningful learning. Med Teach. 27:61-65.

Gavriel J. 2015. Tips on inductive learning and building resilience. Educ Prim Care. 26:332-334.

Gentile JR. 2000. Learning, transfer of. In: Kazdin AE, Kazdin AE, editors. Encyclopedia of psychology, Vol. 5. Washington (DC); New York (NY): American Psychological Association, Oxford University Press; $p$ 13-16.

Harden RM, Sowden S, Dunn WR. 1984. Educational strategies in curriculum development: the spices model. Med Educ. 18:284-297.

Huwendiek S, Duncker C, Reichert F, De Leng BA, Dolmans D, van der Vleuten CP, Haag M, Hoffmann GF, Tonshoff B. 2013. Learner preferences regarding integrating, sequencing and aligning virtual patients with other activities in the undergraduate medical curriculum: a focus group study. Med Teach. 35:920-929.
Jones VS, Holland AJ, Oldmeadow W. 2008. Inductive teaching method-an alternate method for small group learning. Med Teach. 30:e246-e249.

Kapur M. 2016. Examining productive failure, productive success, unproductive failure, and unproductive success in learning. Educ Psychol. 51:289-299.

Kirschner PA, Sweller J, Clark RE. 2006. Why minimal guidance during instruction does not work: An analysis of the failure of constructivist, discovery, problem-based, experiential, and inquiry-based teaching. Educ Psychol. 41:75-86.

Prince MJ, Felder RM. 2006. Inductive teaching and learning methods: definitions, comparisons, and research bases. J Eng Educ. 95: 123-138.

Rotgans Jl, Schmidt HG. 2011. The role of teachers in facilitating situational interest in an active-learning classroom. Teach Teach Educ. 27:37-42.

Schmidt HG, Rikers RM. 2007. How expertise develops in medicine: knowledge encapsulation and illness script formation. Med Educ. 41:1133-1139.

Schmidt HG, Rotgans Jl, Yew EH. 2011. The process of problem-based learning: what works and why. Med Educ. 45:792-806.

Schmidt HG, Wagener SL, Smeets GA, Keemink LM, van der Molen HT. 2015. On the use and misuse of lectures in higher education. Health Prof Educ. 1:12-18.

Schraw G, Flowerday T, Lehman S. 2001. Increasing situational interest in the classroom. Educ Psychol Rev. 13:211-224.

Van Merrienboer JJ, Sweller J. 2010. Cognitive load theory in health professional education: design principles and strategies. Med Educ. 44:85-93.

Vandewaetere M, Manhaeve D, Aertgeerts B, Clarebout G, Van Merrienboer JJ, Roex A. 2015. 4c/id in medical education: how to design an educational program based on whole-task learning: AMEE guide no. 93. Med Teach. 37:4-20.

Wijnia L, Loyens SM, van Gog T, Derous E, Schmidt HG. 2014. Is there a role for direct instruction in problem-based learning? Comparing studentconstructed versus integrated model answers. Learn Instr. 34:22-31.

Young JQ, Van Merrienboer J, Durning S, Ten Cate O. 2014. Cognitive load theory: implications for medical education: AMEE guide no. 86. Med Teach. 36:371-384. 